\title{
FEATURES OF THE CONTRACT FOR ENGINEERING SERVICES IN CIVIL LAW OF UKRAINE: WAYS TO IMPROVE THE PROCESS IN THE CONTEXT OF IMPROVING BUSINESS
}

\author{
Yuliya GLADO (1) ${ }^{*}$, Oleksandra YAVORSKA (D) 2 , Leonid TARASENKO®3, \\ Olena TSILMAK ${ }^{1} 4$, Tetiana MATIIENKO®5 \\ ${ }^{1-3}$ Department of Intellectual Property, Information and Corporate Law, \\ Ivan Franko National University of Lviv, Lviv, Ukraine \\ ${ }^{4}$ Department of Sociology and Psychology, National University "Odessa Law Academy", Odessa, Ukraine \\ ${ }^{5}$ Department of Forensic Science and Psychology, Odessa State University of Internal Affairs, Odessa, Ukraine
}

Received 9 September 2020; accepted 19 October 2021

\begin{abstract}
The current state of regulation of the engineering services market in the world is at the level of constant development and improvement. The formation of a system for concluding contractual relations in the field of engineering services is no exception. The imperfection of the system for concluding the contract for engineering services indicates the weak state of the current management system in the field of innovation and intellectual property in the field of doing business both in a single country and throughout the world, which necessitates revising and improving the principles of concluding contracts in the field of engineering services. The contract for engineering services appeared in the world legislation relatively recently, in science there is still no unity in understanding the nature of this contract, as well as in the terminology used to designate legal relations arising on its basis. There are different, sometimes polar, approaches to the essence, features and elements of the contract for engineering services. In addition, there is still no single mechanism for forming a contract. Given this, an important step towards improving the contract for engineering servicess in civil law will be the formation of a systematic sequence of steps using the IDEF0 functional model. In this regard, the main goal of the article is to form the basic principles of consistency and algorithmization of the process of concluding the contract for engineering servicess on the basis of a functional model IDEF0.
\end{abstract}

Keywords: contract, engineering services, assessing, civil law, IDEF0 model, functional modeling, business sphere.

JEL Classification: D86, K12, K22, L21.

\section{Introduction}

Any legal phenomenon has its own concept, which is aimed primarily at determining its features, goals and the nature of the regulation of relations. This axiom also applies to such a concept as "contract".

An extremely important, in our opinion, element of the characteristics of the contract is the definition of its legal regulation, that is, its legal nature (civil or economic and legal). Taking into account the fact that no normative act has established requirements, the contract for engineering services is executed only by the business entity, we conclude that it is a civil law as a bilateral transaction. But the existence of business customs regarding the fact that the engineering company is usually the executor of engineering services gives grounds to assert that the contract for engineering services is of a mixed nature, that is, such that it is subject to the regulation of at least two institutions.

The parties to the investigated contract are the customer and the contractor. Customers are usually individuals and legal entities. Performers, as practice shows, are specialized engineering companies that specialize in individual links of the engineering cycle or provide a full range of engineering services. Less commonly, performers are individuals.

In terms of the ratio of the subjective rights and legal obligations of the parties to the contract, engineering services can be classified as bilateral synalagmatic (rights and obligations of the parties to foreign relations) contracts. Depending on the availability of a counter exchange

*Corresponding author. E-mail: shtang_an@ukr.net

Copyright $\odot 2021$ The Author(s). Published by Vilnius Gediminas Technical University

This is an Open Access article distributed under the terms of the Creative Commons Attribution License (http://creativecommons.org/licenses/by/4.0/), which permits unrestricted use, distribution, and reproduction in any medium, provided the original author and source are credited. 
property counter equivalent, the contract, we are interested in, we refer to paid, that is, business contracts. Reimbursable should be recognized as contracts in which one party for the fulfillment of his obligation must receive appropriate compensation either in the form of money, then in the form of other material values. Such contracts are consumer and / or business contracts. In the first, the consumer pays a fee for the goods, works or services provided to him to an entrepreneur or another person, he does not have such a status, in the second, a part of the entrepreneur's profit is included in the price of such a product.

Now, in our opinion, an engineering agreement is an agreement of accession, that is, one whose terms are established by one of the parties in forms or other standard forms, which can only be concluded by joining the other party to the proposed agreement.

Engineering services as a multipurpose instrument of cooperation provides opportunities for interaction at various stages of construction, preparation and operation of production facilities. Considering the above, the engineering cycles are also highlighted, in particular:

- research of a specific market situation, in fact it concerns marketing;

- design and development of working technical documents;

- support and provision of post-project services, as well as recommendations for production maintenance of the project.

Engineering services is carried out on a commercial basis, and since a large number of companies specializing in engineering services operate on the world market, the cost of services is quite transparently determined by socially necessary costs.

Since engineering involves a wide variety of services that fall into the engineering category, engineering firms specialize in areas. In this case, such services are understood as in a broad sense, including the services of retail trade and public catering enterprises.

In a broad sense, the following types of engineering firms are distinguished in international practice:

- engineering and consulting - provide services without further supply of equipment;

- engineering and construction - can provide a full range of services related to the creation of industrial and other facilities on a turnkey basis, that is, in a contract;

- advisory - provide services for enterprise management, computer technology, organization of production, sales, finance;

- engineering research - specializing in the development of technological processes and technologies for the production of new materials, that is, contracts for the creation and use of objects of intellectual property, also belongs to the suborder.

The conclusion of the contract for engineering services is subject to the general rules for the conclusion of contracts, but they have their own characteristics, in particular, in the possibility of using the scheme of a connection agreement. In practice, the provision of engineering services is often combined with the sale of know-how. In this case, the "know-how" is hidden and does not stand out as an independent transaction. This leads to confusion between the concepts of "engineering services" and "technology exchange". In fact, engineering services are a way of transferring new technological and other knowledge, but the services themselves are a commodity different from technology. Engineering firms, for example, in the field of management are not engaged in planning, but in the development of new methods for planning production of products based on marketing research of the external market, not in accounting and reporting, but in the search for new approaches to accounting and reporting, modernization of management structures, product quality control, etc.

But despite the existence of a wide range of engineering services today, contracts for the provision of these services are still imperfect and need to be improved. Taking this into account, according to the authors, the process of forming and concluding the contract for engineering services can be improved with the help of functional modeling IDEF0 in the context of improving business.

\section{Literature review}

Over the past decade, attention has increased in all country's to the understanding and use of engineering services, which is very common in developed countries and is widely used in almost any field of human activity: aerospace, construction, economics, energy, information technology, mechanical engineering, metallurgy, agriculture, pharmacology, chemical industry, etc. Engineering aims to obtain the best results from capital investments in the implementation of projects through the achievements of science. With the help of engineering services, it is possible to achieve shorter project times, reduce investment, reduce production costs per unit of output.

A significant number of scientists have studied the development of the conclusion and effective implementation of the contract for engineering services. For example, Vedeneev (2006) considered the main elements and features of the management process during the implementation of the contract for engineering services for business development.

At the same time, Golovkin (2020) explored the main elements of the legal and economic field in the field of concluding and fulfilling the terms of the contract for engineering services.

Marshall (1998) considered the main elements of a financial contract for engineering services and its main financial aspects.

The main basic conceptual aspects of the contract for engineering services and its impact on business development can be observed in studies of a large number of leading scientists (Kvaktun, 2013; Kanzafarova, 2007; Zaychuk, 2006; Drozdova, 2004; Zhilinkova, 2011; Gorodiskaya, 2012). 
Peculiarities of providing the resource basis of the contract for engineering services were studied in the work of Kirichenko (2020).

Features of modern elements of the contract for engineering services can be found in the works of Perry (1995). The main challenges facing the formation and implementation of the contract for engineering services in the context of business development, studied Lau et al. (2019) and Whyte and Donaldson (2015).

Given the contribution of leading scientists in this field of research, we still decide to bring mathematical modeling into this complex and multifaceted aspect in order to improve it.

To simulate the process of signing the contract for engineering services in the context of business development, we used the functional modeling methodology. One of such modern methods of scientific knowledge is the IDEF0 notation, which allows you to create a functional model of the structure, functions, information flows and objects of the system under study. Initially, this model was largely used in the field of economics and modeling of basic business processes (Sylkin et al., 2019).

Later, given the simplicity and clarity of the IDEF0 model, it was used by various scientists for various purposes (Yanchuk \& Shulgan, 2019; Chernyaga \& Yanchuk, 2012; Haihong et al., 2012; Cheung et al., 2003; Yachmen, 2020 and others).

But it is worth noting that the overwhelming majority of authors whose works we studied used this model at a basic level and only in order to simplify as much as possible the processes of occurring in their research system. Even the functional model developed by Yachmen (2020) cannot be considered ideal, since it is static, while our model is flexible, since adjustments can be made at each stage of its use. the use of information about subprocesses, which affects the main stages of modeling.

\section{Research model}

The IDEF0 methodology has found wide acceptance and application, primarily due to the simple graphical notation used to build the model. The main components of the model are diagrams. They display the functions of the system in the form of rectangles, as well as the connections between them and the external environment through arrows. Using only two graphic primitives (rectangle and arrow) allows you to quickly explain the rules and principles of IDEF0 diagramming to people unfamiliar with this methodology. This advantage allows you to maximally facilitate process describing business processes using a formal and visual graphic language.

The IDEF0 methodology prescribes the construction of a hierarchical system of diagrams - single descriptions of system fragments. First, a description of the system as a whole and its interaction with the outside world is carried out (context diagram), after which a functional decomposition is carried out - the system is divided into subsystems and each subsystem is described separately (decomposition diagrams). Then each subsystem is broken down into smaller ones, and so on until the desired level of detail is achieved.

Each IDEF0-diagram contains blocks and arcs. The blocks represent the functions of the simulated system. Arcs link blocks together and represent the interactions and relationships between them.

Functional blocks (work) in diagrams are represented by rectangles, meaning named processes, functions or tasks that occur over time and have recognizable results. The name of the work should be expressed by verbal nouns denoting the action.

Each side of the block has a specific, well-defined purpose. The left side of the block is for inputs, the top is for control, the right is for outputs, and the bottom is for mechanisms. This designation reflects certain system principles: inputs are converted into outputs, control limits or prescribes the conditions for performing conversions, mechanisms show what and how a function performs. Blocks in IDEF0 are arranged in order of importance, as the author of the diagram understands it.

The arrangement of blocks on the page reflects the author's definition of dominance. Thus, the topology of the

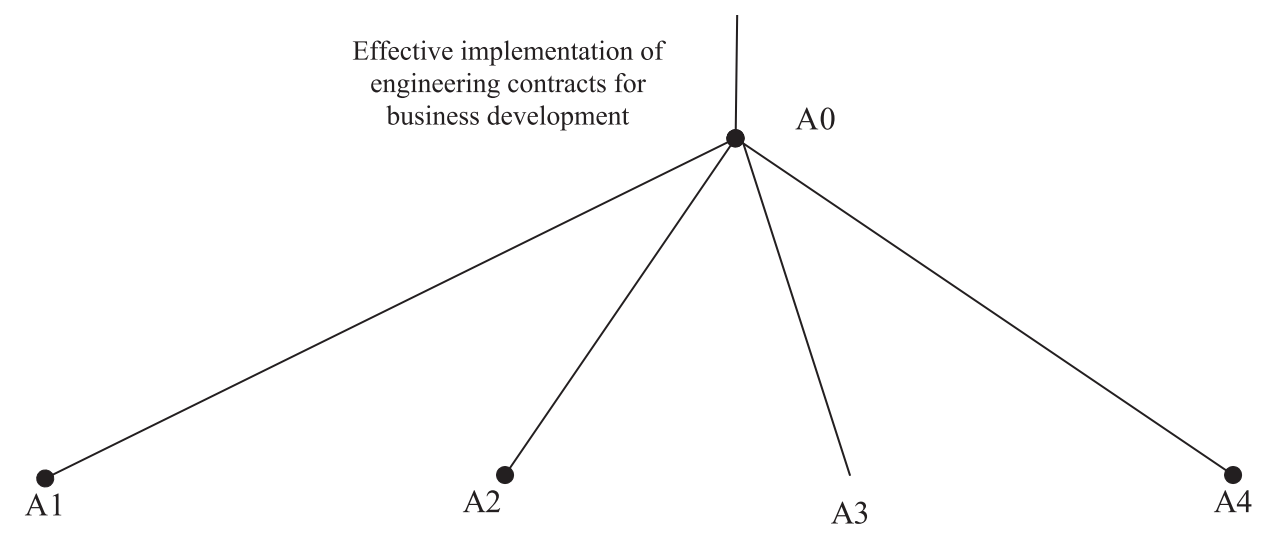

Determination of the

Previous meeting of the parties

Determination of the main terms of the contract

Final conclusion of the contract parties to the contract

Figure 1. Hierarchical structure of the IDEF0 functional model for the effective implementation of the contract for engineering services for business development 
diagram shows which features have the greatest impact on the others.

In order to begin to form the basic structure of the functional model, the first step should be the creation of a high-level functional diagram A0, in which the main steps will be defined, in accordance with which the decomposition of the next levels will be formed. With this in mind, Figure 1 shows the main stages of the formation of the contract for engineering services.

It is worth making a note that this model is not universal, because it does not take into account the specifics of public procurement and the tender process. The plans for further research are to complement this model, making it universal, regardless of whether contracts are concluded between private organizations or through public procurement procedures.

The schematic drawing formed by us makes it possible to visually depict the entire list of basic steps that arise in the course of concluding the contract for engineering services. This hierarchical structure is a simplified algorithm for the entire process we are investigating and at the same time, there are possibilities for making local changes and subsequent modification of the entire process of concluding an agreement.

\section{Results and discussion}

In order to make full use of all the functional properties of the functional model IDEF0, the next step in our study will be the formation and selection of the main elements necessary for the implementation of the main method A0 (Figure 2). To do this, you need to build a context diagram, where each block demonstrates the very essence of the process of converting inputs to outputs, using certain volumes and types of resources.

A context diagram is a high-level diagram that represents the system as a whole, in the form of a data block, and further connects it with the outside world using interface arcs. Taking this into account, we can conclude that the very essence of the context diagram is the formation of the modeling area and its boundaries.

In order to detail and simplify the understanding of our proposed model, the next step in our research will be to explain each element of the presented context diagram.

The input elements, denoted by the symbols "I" with the corresponding numbering, indicate financial, material, as well as information and technical resources necessary for the effective implementation of the contract for engineering services for business development.

In context blue data, control object diagrams are displayed using the "C" symbol and indicate the following:

$\mathrm{C} 1$ - projects and plans. This element denotes the documentary support of the process by which the current control and monitoring of the compliance of the documented specified norms will take place.

$\mathrm{C} 2$ - regulatory support. This element will correspond to that part of the control elements that are contained in the regulatory documents of one or both parties to the agreement. To a large extent, this part of the control will

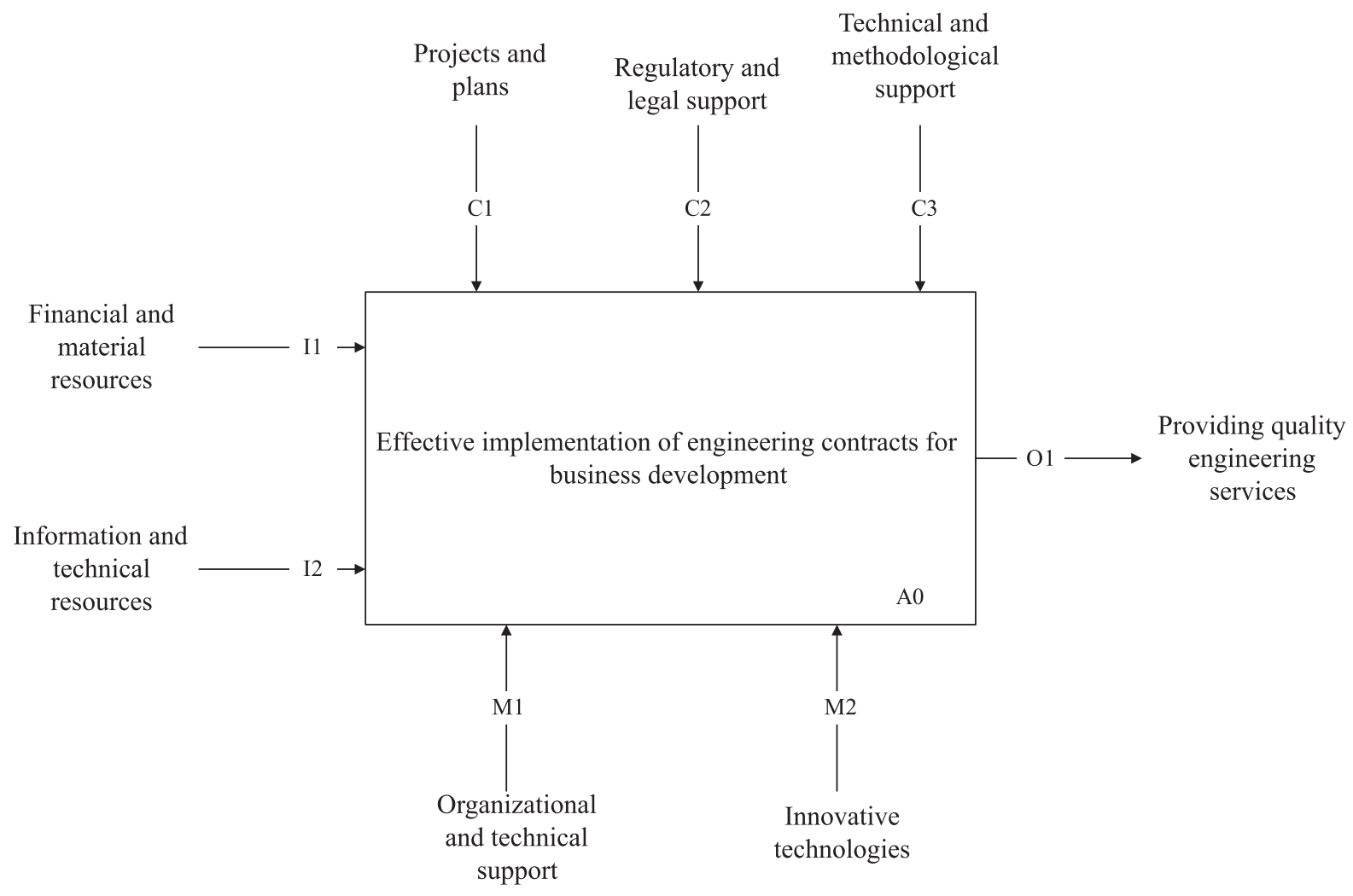

Figure 2. Context diagram of the IDEF0 model elements of the main ways to improve the process of implementing the contract for engineering services for business development (developed by the authors) 
monitor the prevention of violations of legislative and internal regulations and rules.

C3 - technical and methodological support is responsible for control over the technical and methodological component of the process of concluding the contract for engineering services.

The objects of the mechanism are designated in this contextual dagrams by the symbol " $\mathrm{M}$ " and denote the following:

M1 - organizational and technical support, responsible for securing the organizational part of the process of concluding the contract for engineering services.

M2 - Innovative technologies. Considering that the process of concluding the contract for engineering services is a process that is undergoing constant modification and improvement, innovative technologies, in our opinion, are a powerful mechanism to ensure the process of concluding the contract for engineering services.

The final part of this context diagram is the elements of the final result, to which the entire functional model follows. In our case, this element will be marked with the "O" symbol and denote the provision of quality engineering services as a result of the implementation of an optimized and correct the contract for engineering services.

After we have depicted all the functional elements of the A0 context diagram, the next step is to form possible transformations and interactions that will lead to the expected end result. To do this, we had a formed decomposition of the first level of the process of concluding the contract for engineering services (Figure 3 ).

Decomposition of the first level of the functional model IDEF0 in our case will be the initial stage and starting point for the formation of the next decomposition, which in turn can become the basis for the formation of the next decomposition. This feature of the functional model allows users to fully detail and simplify the process of implementing the contract for engineering services, thereby working through all the functional steps and elements.

For a better understanding, it will be advisable to explain the essence of each of the stages of the process of implementing the contract for engineering services:

A1 - determination of the parties to the contract. At this stage, an initial meeting and agreement of the main subjects of the engineering agreement takes place.

A2 - preliminary meeting of the parties. At this stage, the parties who will take part in the contract to the engineer in an informal setting will discuss the main steps and critical points of a separate contract. At this stage, the end result can be considered the coordination of the main interests of each party and agreement to continue the process of concluding the contract for engineering services.

A3 - determination of the main terms and of the contract. At this stage, all the elements of the contract are officially agreed upon.

A4 - the final conclusion of the contract. After all the conditions and critical points of the contract for engineering services have been agreed and the parties to the contract have no other obstacles to accepting this contract, the stage of final signing of the contract for engineering services begins.

It is worth noting that each stage indicated by the symbol " $\mathrm{A}$ " can seem to be detailed and the process of achieving it will be transformed into a separate decomposition. In our case, we have chosen stage number 3 and, on its basis, a separate decomposition of the functional model has been formed (Figure 4).

In addition to the elements already mentioned by us, the decomposition of both the first and the second levels contains intermediate inputs, outputs and control mechanisms; they are depicted in the decomposition as arrows and blocks:

directives ensure subprocesses, which can be presented as orders and instructions of subjects who are endowed with control rights in this process.

subprocesses progress information, which can be presented in the form of functionally important information that is received by subjects who have control rights in this process. Based on this information, a decision is made on the completion or extension of a separate stage of implementation of the contract for engineering services.

It should be noted that, if necessary, users of this methodology have the ability to build the following levels of decomposition. This will be a useful element in case the process of accepting the contract for engineering services is difficult for any reason.

This model is not a static method for concluding contracts with an engineer, since it does not take into account the influence of external and internal factors in the first place, but at the same time it can become a powerful fundamental basis for the formation of our own systems for the implementation of contract engineering and further development of our own business.

\section{Conclusions}

Today, the basic essence of engineering services lies in the field of doing business, or rather venture entrepreneurial activity, the main part of which is intellectual innovation and such that should be carried out by qualified specialists in the relevant field. Due to its versatility, engineering services is used in the implementation of business projects of a different nature: research, design and construction, production, sales, etc. Contract for engineering services refers to civil law contracts. To regulate relations under such contracts, the general provisions of contract law and the contracts directly used in practice are applied. The customer under the contract for engineering services can be: individuals, legal entities, state bodies and local authorities, and the performers under these contracts can be individuals - professionals, legal entities that specialize in the provision of engineering services. Given the great relevance of the implementation of contractual relations in the field of engineering services, today it is of particular importance to form stable and optimized mechanisms for 


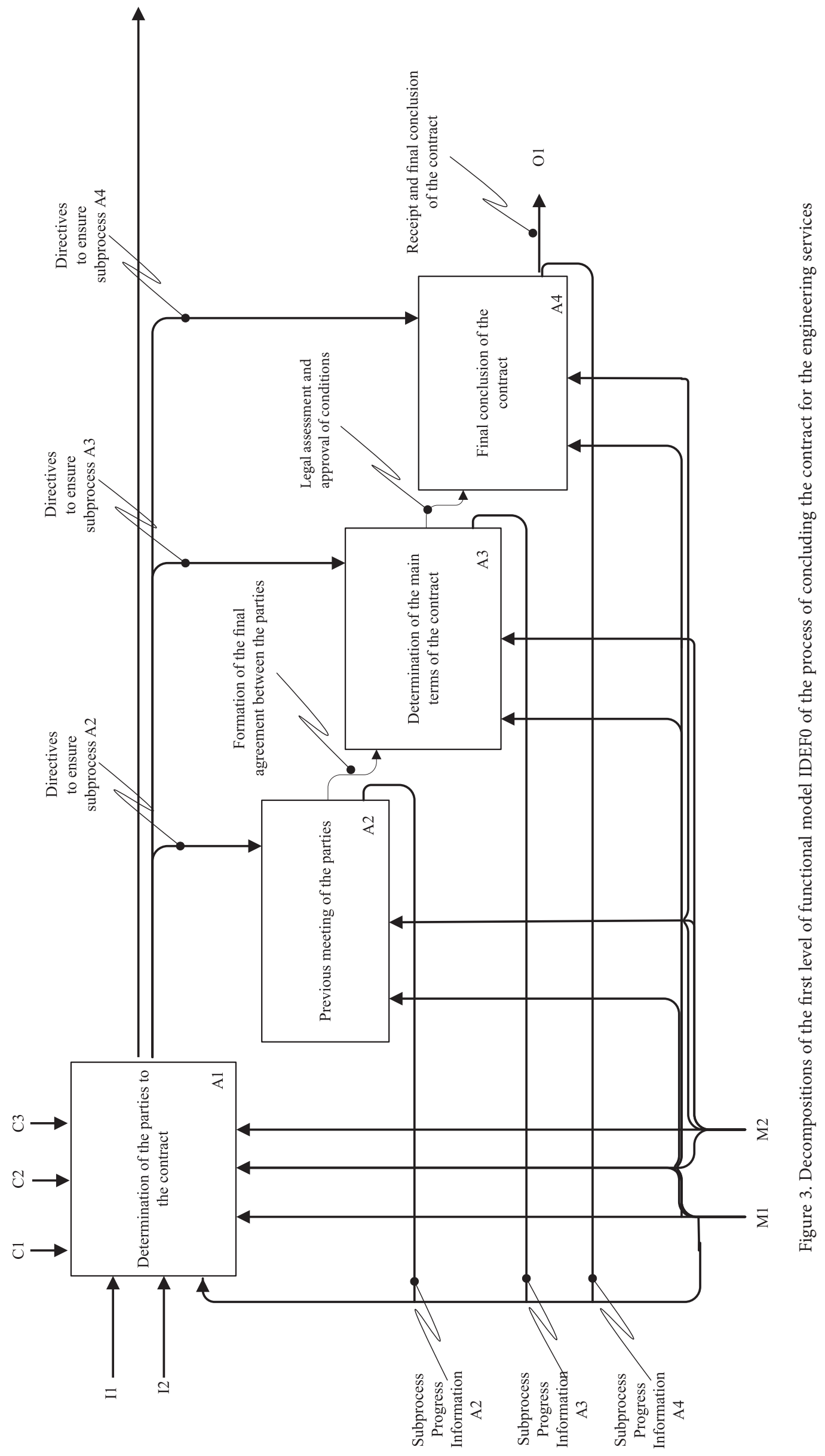




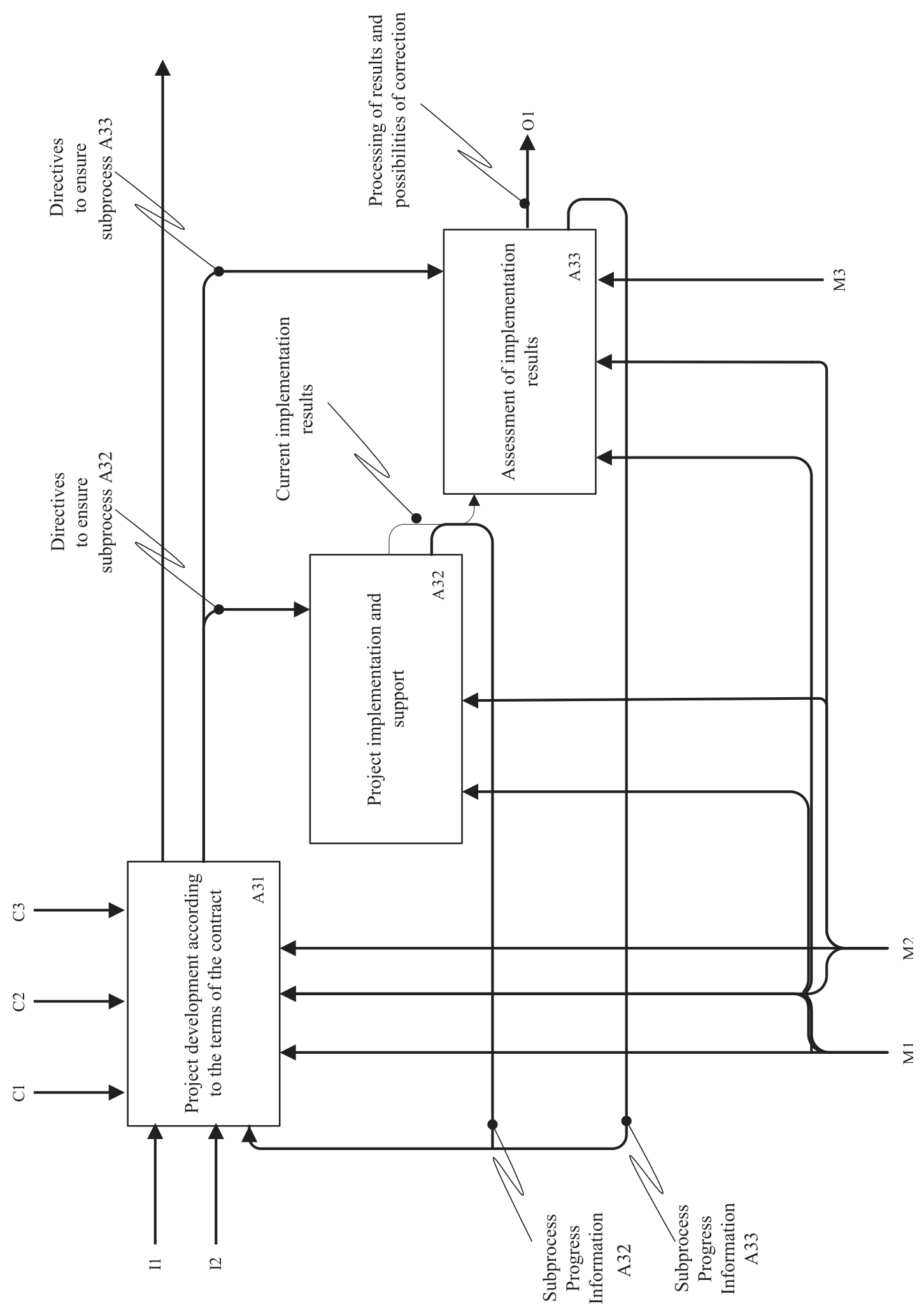


concluding contracts in the field of engineering services. Taking this into account, the authors proposed to use a functional model IDEF0 to form a visual display of the process of concluding the contract for engineering services. The advantages of using this model can be considered that it is universal and can change in accordance with changes in the initial conditions. In addition, the decomposition of this model can include an infinite number of levels, which is useful if there is a need to specify goals or create additional conditions.

This model cannot be considered universal, because it does not take into account the specifics of public procurement and the tender process. In further research, the authors plan to complement this model by making it universal, regardless of whether contracts are between private organizations or through public procurement procedures. The study has limitations, since only the legislative framework of Ukraine was used, but there are reasons for this, since in the context of the pandemic and the geographical location of the authors, it was difficult to study the specifics of the the contract for engineering services in the context of the legislative frameworks of other countries.

\section{Author contributions}

The authors contributed equally.

\section{Disclosure statement}

The authors do not have any conflict of interest.

\section{References}

Chernyaga, P., \& Yanchuk, O. (2012). The order of value access point for GPS - be careful in the minds of obscured appearances. Nowadays Access to Geodesic Science and Technology, 23(2), 53-56.

Cheung, Ch.-K., Rudowicz, E., Yue, X., \& Kwan, A. S. F. (2003). Creativity of university students: What is the impact of field and year of study? Journal of Creative Behavior, 37(1), 42-63. https://doi.org/10.1002/j.2162-6057.2003.tb00825.x

Drozdova, G. M. (2004). Management of foreign economic activity of an enterprise [textbook]. Center for Educational Literature.

Golovkin, R. (2020). Legal engineering: Essence and relationship with legal technique.

https://socionet.ru/d/spz:cyberleninka:15690:16688570/ http://cyberleninka.ru/article/n/yuridicheskiy-inzhiniringsuschnost-i-sootnoshenie-s-yuridicheskoy-tehnikoy

Gorodiskaya, N. A. (2012). The concept of engineering and its meaning in the market conditions of management. National University "Lviv Polytechnic".

http://ena.lp.edu.ua:8080/handle/ntb/13849
Kanzafarova, I. (2007). Theoretical foundations of civil liability in Ukraine [dissertation, Institute of State and Law]. Kiev.

Kirichenko, Yu. S. (2020). Ensuring the fulfillment of contractual obligations in modern conditions.

http://intkonf.org/kirichenko-yus-zabezpechennyavikonannya-dogovirnih-zobovyazan-v-suchasnih-umovah/

Kvaktun, A. A. (2013). Classification of engineering services in GATS. In Special Project: Analysis of Scientific Research: Materials of the VIII International Scientific Methodology Internet Conference. http://www.confcontact.com/2013specproekt/ek2_kvaktun.htm

Lau, C. H., Mesthrige, J. W., Lam, P. T. I., \& Javed, A. A. (2019). The challenges of adopting new engineering contract: A Hong Kong study. Engineering, Construction and Architectural Management, 26(10), 2389-2409.

https://doi.org/10.1108/ECAM-02-2018-0055

Marshall, J. (1998). Financial engineering. Infra-M.

Perry, J. G. (1995). The new engineering contract: principles of design and risk allocation. Engineering, Construction and Architectural Management, 2(3), 197-208. https://doi.org/10.1108/eb021011

Sylkin, O., Kryshtanovych, M., Zachepa, A., Bilous, S., \& Krasko, A. (2019). Modeling the process of applying anti-crisis management in the system of ensuring financial security of the enterprise. Business: Theory and Practice, 20, 446-455. https://doi.org/10.3846/btp.2019.41

Vedeneev, F. V. (2006). Project management of engineering activities [dissertation]. Moscow.

Wang, H., Gong, G., Xie, J., Cai, S., \& Zheng, Y. (2012). Research on IDEF0 and UML combination based modeling of equipment support. In T. Xiao, L. Zhang, \& M. Fei (Eds.), AsiaSim 2012. Communications in Computer and Information Science, Vol. 323. Springer. https://doi.org/10.1007/978-3-642-34384-1_7

Whyte, A., \& Donaldson, J. (2015). Digital model data distribution in civil engineering contracts. Built Environment Project and Asset Management, 5(3), 248-260. https://doi.org/10.1108/BEPAM-02-2014-0009

Yachmen, F. (2020). Functional model initial mortgage in IDEF0. Business Information, 4(1), 91-98.

Yanchuk, O., \& Shulgan, R. B. (2019). Resheniye zadach zemleustroystva i kadastra s ispol'zovaniyem matematicheskoy modeli dlya soznaniy nevazhnykh [Solution of tasks land management and cadastre with using mathematical model for the minds of non-significance]. Newsletter of the National University of Water Statehood and Nature Criticism. "Technology", 3, 293-300.

Zaychuk, O. V. (2006). Theory of state and law. Academic course [textbook]. Odyssey.

Zhilinkova, A. A. (2011). Implementation of intellectual property rights on the Internet using Creative commons licenses. Legal Journal, 53(2), 54-60. 